\title{
COVID-19-related delays of botulinum toxin injections have a negative impact on the quality of life of patients with dystonia and spasticity: a single-center ambulatory care study
}

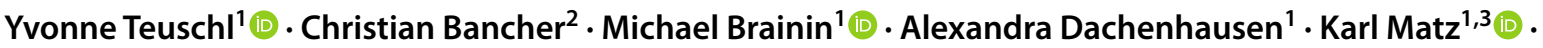 \\ Michaela M. Pinter ${ }^{1,2}$ (D)
}

Received: 23 August 2021 / Accepted: 8 October 2021 / Published online: 23 October 2021

(c) The Author(s) 2021

\begin{abstract}
Background Botulinum toxin A (BoNT-A) is considered a safe and effective treatment for spasticity and dystonia. Individual interinjection intervals are critical for the maintenance of the effect. In Austria, BoNT outpatient clinics were shutdown from November to December 2020 during COVID-19 control measures, leading to rescheduling of BoNT-A injections. This survey aimed at investigating the influence of injection delays on symptoms, physical functioning, and quality of life (QoL) of the affected patients.

Methods Between April and July 2021, 32 outpatients (21 females, mean age: $63.4 \pm 12.1$ years) treated $\geq 12$ months at the BoNT outpatient clinic Horn-Allentsteig (Austria) and experienced $\geq 2$ week injection delays, completed a structured face-to-face questionnaire.

Results Indications were dystonia (34\%), spasticity (63\%), and hyperhidrosis (3\%). Injections were delayed by 10 weeks (median, range: 2-15). Muscle cramps increased in 95\% of patients with spasticity, muscle twitches in $91 \%$ of those with dystonia, and pain in $9 \%$ and $60 \%$ for dystonia and spasticity, respectively. Overall, 75\% reported functional worsening, and deterioration in QoL by $62.6 \% \pm 16.8$ (mean $\pm \mathrm{SD}$ ). The impact on QoL correlated with the subjective global improvement induced by BoNT-A (Rs: $0.625 ; p<0.001$ ). For $75 \%$, long-term assurance of BoNT-A therapy was very important, and $81 \%$ felt their patient rights not respected.

Conclusions COVID-19-related delays in BoNT-A injections illustrate the importance of this therapy for symptom relief, functional outcome, and QoL in patients suffering from involuntary muscle hyperactivity. BoNT-A therapy is essential and has to be guaranteed even in circumstances such as the COVID-19 pandemic.
\end{abstract}

Keywords Botulinum toxin therapy $\cdot$ Spasticity $\cdot$ Dystonia $\cdot$ Quality of life $\cdot$ COVID-19 $\cdot$ Patient rights ·

Neurorehabilitation

Michaela M. Pinter

michaela.pinter@donau-uni.ac.at

1 Department for Clinical Neuroscience and Preventive Medicine, Danube University Krems - University for Continuing Education, Dr. Karl-Dorrek Str. 30, 3500 Krems, Austria

2 Department of Neurology, Landesklinikum Horn-Allentsteig, Horn, Austria

3 Department of Neurology, Landesklinikum Baden-Mödling, Mödling, Austria

\section{Introduction}

Botulinum toxin (BoNT-A) is used as standard in medical practice for the treatment of spasticity and dystonia as well as for autonomic syndromes (Dressler et al. 2021; Simpson et al. 2016). BoNT-A is a neurotoxic protein produced by the bacterium Clostridium botulinum, which is injected in the affected muscles and causes muscle relaxation, improvement of symptoms, and can thereby facilitate rehabilitation. It is considered safe and effective for the treatment of dystonia and spasticity; however, there is not sufficient evidence to conclude whether BoNT-A can improve the underlying motor dysfunction (Simpson et al. 2016). The relief of symptoms starts approximately 10 days after the injection, with 
peak effects at 4-6 weeks, and last between 2 and 4 months (Jacinto et al. 2020; Esquenazi et al. 2020). However, longer interval injections may occur in early post-stroke spasticity (Rosales et al. 2018). The maintenance of individual interinjection intervals is critical for functional status and quality of life $(\mathrm{QoL})$ of the affected patients.

In Austria, as in other countries, COVID-19 pandemic countermeasures included shutdowns of all medical activites in hospitals other than for acute life-threatening conditions to protect patients and healthcare providers from the exposure to the disease and to allow shifting staff and facilities to COVID-19 wards and intensive care units. The botulinum toxin outpatient clinic of the hospital Horn-Allentsteig in Austria was closed in November 2020 for 8 weeks, and injections planned for this period had to be rescheduled. After the end of the lockdown, a survey was performed to investigate the influence of injection delays on symptoms and QoL of the affected patients.

\section{Methods}

The botulinum toxin outpatient clinic of the Landesklinikum Horn-Allentsteig treats approximately 700 patients with dystonia, limb spasticity and other indications per year. Due to the COVID-19-related lockdown in November-December 2020, appointments of 50 patients had to be canceled; for 17 of these patients, BoNT-A treatment was delivered during a visit in a neurological practice; however, 33 patients had to be rescheduled until the end of the lockdown. After reopening, all outpatients treated previously for more than 12 months with BoNT-A and experiencing more than 2 weeks of injection delay were invited to complete a structured face-to-face questionnaire during the following visits. Exclusion criteria were serious adverse events such as accidents or severe injuries since the last BoNT-A injection, aphasia making communication impossible, and cognitive impairment (Mini Mental State Examination $<20$ points). Informed consent was obtained by the treating physician (MP). The structured questionnaire created by Dressler and Adib Saberi (2020) was used. It includes six questions about changes in spastic or dystonic symptoms, the impact of the delays of injection intervals on QoL, as well as about patients' perception of the shutdown.

BoNT-A treatment was performed with Incobutulinumtoxin-A (Xeomin $\left.{ }^{\circledR}\right)$, Onabotulinumtoxin-A (Botox $\left.{ }^{\circledR}\right)$ or Abobotulinumtoxin-A (Dysport ${ }^{\circledR}$ ). For comparison, equivalence mouse units (MU-E) were used, by assuming $1 \mathrm{MU}-\mathrm{E}=1 \mathrm{MU}$ Xeomin ${ }^{\circledR}=1 \mathrm{MU}$ Botox ${ }^{\circledR}=1 / 3 \mathrm{MU}$ Dysport ${ }^{\circledR}$.

This study has been approved by the local ethics committee of the Danube University Krems (NUMBER EK GZ 42/2018-2021, March, 24, 2021).

\section{Statistical analysis}

Metric data were described by means and standard deviation, median and quartiles as appropriate, and nominal data by relative frequency. To test for the influence of different demographic, disease-related or treatment-related variables on QoL, Mann-Whitney $U$ test, or Spearman Rang correlations were used for nominal and metric variables, respectively.

\section{Results}

Between April and July 2021, 32 patients ( 21 females, 11 males, mean age: $63.4 \pm 12.1$ ) were recruited for this survey. All eligible patients agreed to participate. One patient was not invited due to time constraints. The indications for BoNT-A treatment were dystonia in 11 (34.4\%), limb spasticity in 20 patients (62.5\%), and hyperhidrosis in one (3.1\%) patient. Dystonia included blepharospasm $(n=6$; $54.5 \%)$, hemifacial spasm $(n=4 ; 36.4 \%)$, and spasmodic torticollis $(n=1,9.1 \%)$. Spasticity was hemiparetic in 13 $(65 \%)$, paraparetic in $3(15 \%)$, and tetraparetic in $4(20 \%)$ patients; the underlying disorders in these patients were ischemic stroke $(n=11)$, hemorrhagic stroke $(n=2)$, multiple sclerosis $(n=4)$, hereditary spastic paralysis $(n=2)$, and unknown $(n=1)$. Overall, patients were treated with BoNT-A in median for 4 years (interquartile range [IQR] $2-8)$, and before the shutdown, the majority (91\%) had interinjection intervals of 12 weeks (median 12, range 8-14 weeks). Most patients were treated with Incobotulinumtoxin-A (78.1\%), $15.6 \%$ with Onabotulinumtoxin-A and $6.3 \%$ with Abobotulinumtoxin-A; the total dose per patient was in median 400 MU-E (IQR: 48-600), but differed according to the affected muscles and thus between patients with dystonia and spasticity (Table 1).

The injections were delayed by 10 weeks in median (IQR 7.5-12.5) with a maximum of 15 weeks. Overall, $97 \%$ of patients reported a worsening of symptoms and $80 \%$ reported that this had an impact on their functional status. Muscle cramps increased in $95 \%$ of patients with spasticity, muscle contractions in $91 \%$ of those with dystonia, and pain increased in 9 and $60 \%$ of patients with dystonia and spasticity, respectively. Patient felt that the prolonged interinjection delay decreased their QoL in mean by $62.6 \pm 16.8 \mathrm{SD}$ (Table 1 ).

Patients who rated their subjective improvement induced by BoNT-A larger perceived also the impact of injection delays on their QoL stronger $(\mathrm{Rs}=0.664$; $p<0.001)$. The impact on QoL was not influenced by sex, 
Table 1 Impact of COVID-19related measures on BoNT-A treatment and patients' quality of life, according to dystonia and spasticity

\begin{tabular}{|c|c|c|c|}
\hline & Dystonia $(n=11)$ & Spasticity $(n=20)$ & All $(n=32)^{1}$ \\
\hline Female & $8(72.7 \%)$ & $12(60.0 \%)$ & $21(65.6 \%)$ \\
\hline Age (years, mean $\pm S D$ ) & $66.9 \pm 13.4$ & $63.1 \pm 9.4$ & $63.4 \pm 12.1$ \\
\hline Treatment duration (years) & $4(3-18)$ & $3.5(2-7)$ & $4(2-8)$ \\
\hline Total dose (MU-E) & $28(20-60)$ & $500(400-650)$ & $400(48-600)$ \\
\hline Clinical Global Improvement (\%) & $80(70-100)$ & $80(50-85)$ & $80(60-95)$ \\
\hline Delay of injection (weeks) & $10(4-11)$ & $11.5(9.5-12.5)$ & $10(7.5-12)$ \\
\hline Impact on $\mathrm{QoL}^{2}($ mean $\pm \mathrm{SD})$ & $63.1 \pm 16.7$ & $61.7 \pm 17.6$ & $62.6 \pm 16.8$ \\
\hline Subjective decrease of function & $9(90 \%)$ & $14(74 \%)$ & $24(80 \%)$ \\
\hline Increase in any symptoms & $11(100 \%)$ & $19(95 \%)$ & $31(97 \%)$ \\
\hline Increase in cramps & $1(9 \%)^{3}$ & $19(95 \%)$ & \\
\hline Increase in pain & $1(9 \%)$ & $12(60 \%)$ & \\
\hline Increase in twitches & $10(91 \%)$ & & \\
\hline \multicolumn{4}{|l|}{ Importance of BoNT therapy } \\
\hline More important than before & $11(100 \%)$ & $14(70 \%)$ & $25(78 \%)$ \\
\hline Similar & $0(0 \%)$ & $6(30 \%)$ & $7(22 \%)$ \\
\hline Less important than before & $0(0 \%)$ & $0(0 \%)$ & $0(0 \%)$ \\
\hline \multicolumn{4}{|l|}{ Importance of assurance of therapy } \\
\hline Very important & $10(91 \%)$ & $13(65 \%)$ & $24(75 \%)$ \\
\hline Important & $1(9 \%)$ & $5(25 \%)$ & $6(19 \%)$ \\
\hline Less important & $0(0 \%)$ & $2(10 \%)$ & $2(6 \%)$ \\
\hline \multicolumn{4}{|l|}{ COVID-19 lockdown was } \\
\hline Adequate & $4(36 \%)$ & $3(15 \%)$ & $7(22 \%)$ \\
\hline Inadequate & $7(64 \%)$ & $17(85 \%)$ & $25(78 \%)$ \\
\hline \multicolumn{4}{|l|}{ Patient rights were } \\
\hline Respected & $4(36 \%)$ & $2(10 \%)$ & $6(19 \%)$ \\
\hline Not respected & $7(64 \%)$ & $18(90 \%)$ & $26(81 \%)$ \\
\hline
\end{tabular}

BoNT-A botulinum toxin A, $M U-E$ equivalent of mouse units, $Q o L$ quality of life, $S D$ standard deviation Values are numbers (percentages) or median (interquartile range) if not state otherwise

${ }^{1}$ Including the patient with hyperhidrosis

${ }^{2}$ Measured on a visual analogue scale ranging from 0 to 100 with 100 representing the largest impact

${ }^{3}$ Patient with spasmodic torticollis age, indication (dystonia or spasticity), treatment duration, total dose, or the delay of the injection (all $p>0.3$ ).

In patients suffering from spasticity, the effect on QoL was greater in those with voluntary motor function $(n=14$, mean $66.8 \pm 14.9 \mathrm{SD})$ compared to those without $(n=4$, $43.8 \pm 15.7$; Fig. 1$)$.

After the lockdown, BoNT-A therapy has become more important to $78 \%$ of patients. For $75 \%$ of patients, long-term assurance of BoNT-A therapy was very important, 78\% perceived the COVID-19-related lockdown as inadequate and $81 \%$ felt their patient rights not respected (Table 1).

\section{Discussion}

This survey shows how strongly the closure of a botulinum toxin outpatient clinic in Austria and thereby prolonged interinjection intervals affected patients' symptom reoccurrence and their QoL. Case reports and surveys from Italy, the USA, Germany, and the Philippines have already shown the negative influence of COVID-19-related delays of BoNT-A injections on patients suffering from dystonia, spasticity, or migraine (Dressler and Adib Saberi 2020; Ali 2020; Ranza et al. 2020; Erro et al. 2021; Santamato et al. 2021; Tarantino et al. 2021; Samadzadeh et al. 2021; Pajo et al. 2021). This is underlined by $75-91 \%$ of patients perceiving the security of long-term BoNT-A therapy as very important and 76-98\% which felt their patient rights not respected by COVID-19 counter measures (this study, Dressler and Adib Saberi 2020; Tarantino et al. 2021).

In our study, the injection delays were in median 10 weeks, i.e., the interinjection intervals were 22 weeks. In a study investigating the perception of BoNT-A therapy in patients with spasticity of different etiology, symptoms re-occurred in mean 12-13 weeks after the injection, with symptoms being mild to moderate at the beginning and more 


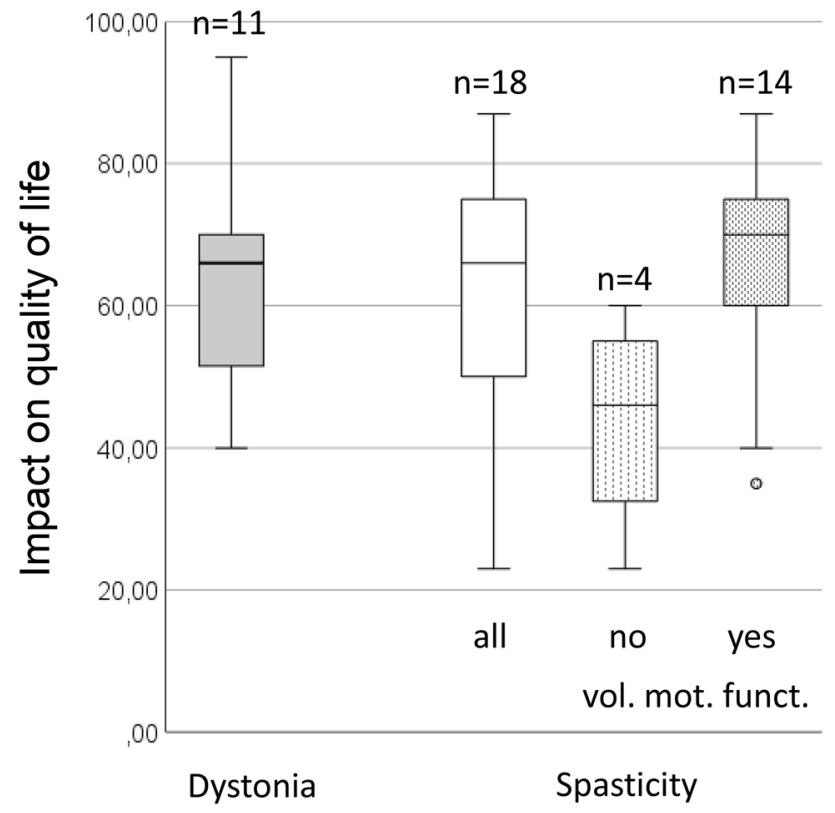

Fig. 1 Impact of delays in botulinum toxin injections on quality of life of patients with dystonia, spasticity, and in the subgroups of patients with spasticity with or without voluntary motor function (vol. mot. funct)

severe on day before the reinjection (Jacinto et al. 2020). Similarly, in a study on Abobotulinumtoxin-A, more than $60 \%$ of adult patients with limb spasticity had required reinjections within 12 weeks and all before 24 weeks; only a few patients with cervical dystonia did not require reinjection within 24 weeks (Esquenazi et al. 2020). However, our study included only one patient with cervical dystonia.

An Italian study reported worsening of symptoms in $72 \%$, a negative impact on QoL in 71\%, and a loss of independence in 53\% of patients after COVID-19-related discontinuation of their usual BoNT-A treatment for spasticity (Santamato et al. 2020). In a German cohort, 44 of 48 (92\%) patients reported a worsening of symptoms after delays in reinjection. This is comparable to the $97 \%$ found in our study (Samadzadeh et al. 2021). The authors calculated that on average, 1 day of delay caused $1 \%$ of worsening compared to the previous visit, with a mean delay of 23 days corresponding to a mean worsening of $26 \%$. In accordance with this, the three times longer delay in our study resulted in a reduction of QoL by $63 \%$. Similarly, Erro et al. (2021) found a mean impact of 5 on 10 points scale after a delay of 10.6 weeks, and Dressler and Adib Saberi (2020) reported a reduction in QoL of $40 \%$ after 6.6 weeks. In Italian patients with cerebral palsy, QoL was reduced by $68 \%$ after a 9 month delay in BoNT-A therapy (Tarantino et al. 2021).

In our study, patients reported that the reoccurrence of symptoms had a strong impact on participation, for example due to functional blindness or to worsening of walking abilities. The impact of the interinjection delay on QoL was strongest for patients which subjectively profited most from the BoNT-A treatment. QoL was less affected in patients with spastic paresis with no remaining motor function, possibly because benefits of therapy had less influence on their activities of daily life.

Limitations of our study are the low number of participants, the absence of a control group, and that functional status was not assessed objectively. Other factors related to the COVID-19 countermeasures such as cessation of physiotherapy or psychosocial stress could have contributed to the lower QoL. Nevertheless, the waning of BoNT-A effects on symptoms and participation have already been reported before the COVID-19 pandemic (Jacinto et al. 2020; Esquenazi et al. 2020).

Our results emphasize the importance of ensuring the individual BoNT-A interinjection intervals for these patients. This has to be guaranteed even in circumstances such as the COVID-19 pandemic and can be achieved with security measures minimizing the risk of infection (Pajo et al. 2021; Baricich et al. 2020).

Acknowledgements The authors thank all the patients who participated in this survey. They further thank Helga Theisl and Doris Gressl for their indispensable assistance during the patient visits at the botulinum toxin outpatient clinic.

Funding Open access funding provided by Danube University Krems University for Continuing Education. No funds, grants, or other support was received for conducting this study.

Availability of data and materials Data are available on request from the authors.

Code availability Not applicable.

\section{Declarations}

Conflict of interest The authors have no conflicts of interest to declare that are relevant to the content of this article.

Ethical approval This study has been approved by the local ethics committee of the Danube University Krems (NUMBER EK GZ 42/20182021, March, 24, 2021).

Consent to participate Verbal informed consent was obtained from all individual participants prior to the interview.

Consent for publication Not applicable.

Open Access This article is licensed under a Creative Commons Attribution 4.0 International License, which permits use, sharing, adaptation, distribution and reproduction in any medium or format, as long as you give appropriate credit to the original author(s) and the source, provide a link to the Creative Commons licence, and indicate if changes were made. The images or other third party material in this article are included in the article's Creative Commons licence, unless indicated otherwise in a credit line to the material. If material is not included in 
the article's Creative Commons licence and your intended use is not permitted by statutory regulation or exceeds the permitted use, you will need to obtain permission directly from the copyright holder. To view a copy of this licence, visit http://creativecommons.org/licenses/by/4.0/.

\section{References}

Ali A (2020) Delay in Onabotulinumtoxin-A treatment during the COVID-19 pandemic-perspectives from a virus hotspot. Headache 60:1183-1186. https://doi.org/10.1111/head.13830

Baricich A, Santamato A, Picelli A, Morone G, Smania N, Paolucci S, Fiore $\mathrm{P}$ (2020) Spasticity treatment during COVID-19 pandemic: clinical recommendations. Front Neurol 11:719. https://doi.org/ 10.3389/fneur.2020.00719

Dressler D, Adib Saberi F (2020) Botulinum toxin therapy in the SARS-CoV-2 pandemic: patient perceptions from a German cohort. J Neural Transm 127:1271-1274. https://doi.org/10.1007/ s00702-020-02235-6

Dressler D, Altavista MC, Altenmueller E, Bhidayasiri R, Bohlega S, Chana P, Chung TM, Colosimo C, Fheodoroff K, Garcia-Ruiz PJ, Jeon B, Jin L, Kanovsky P, Milanov I, Micheli F, Orlova O, Pandey S, Pirtosek Z, Relja M, Rosales R, Sagástegui-Rodríguez JA, Shahidi GA, Timerbaeva S, Wan X, Walter U, Saberi FA (2021) Consensus guidelines for botulinum toxin therapy: general algorithms and dosing tables for dystonia and spasticity. J Neural Transm 128:321-335. https://doi.org/10.1007/ s00702-021-02312-4

Erro R, Scannapieco S, Russo M, Picillo M, Barone P (2021) Impact of COVID-19 on neurological patients attending a botulinum toxin service. Neurol Sci 42:433-435. https://doi.org/10.1007/ s10072-020-04940-2

Esquenazi A, Delgado MR, Hauser RA, Picaut P, Foster K, Lysandropoulos A, Gracies JM (2020) Duration of symptom relief between injections for Abobotulinumtoxin-A (Dysport $\left.{ }^{\circledR}\right)$ in spastic paresis and cervical dystonia: comparison of evidence from clinical studies. Front Neurol 11:576117. https://doi.org/10.3389/fneur. 2020.576117

Jacinto J, Varriale P, Pain E, Lysandropoulos A, Esquenazi A (2020) Patient perspectives on the therapeutic profile of botulinum neurotoxin type-A in spasticity. Front Neurol 11:388. https://doi.org/ 10.3389/fneur.2020.00388
Pajo AT, Espiritu AI, Jamora RDG (2021) Impact and challenges of the COVID-19 pandemic on patients requiring botulinum toxin A treatment. J Mov Disord 14:29-33. https://doi.org/10.14802/ jmd. 20088

Ranza E, Mammi P, Rampello A, Annamaria S, Brianti R (2020) Botulinum toxin therapy during the COVID-19 outbreak: experience of an Italian multidisciplinary team. Eur J Neurol. https://doi.org/ 10.1111/ene. 14569

Rosales RL, Balcaitiene J, Berard H, Maisonobe P, Goh KJ, Kumthornthip W, Mazlan M, Latif LA, Delos Santos MMD, Chotiyarnwong C, Tanvijit P, Nuez O, Kong KH (2018) Early AbobotulinumtoxinA (Dysport $\left.{ }^{\circledR}\right)$ in post-stroke adult upper limb spasticity: ONTIME Pilot Study. Toxins 10:253. https://doi.org/10.3390/toxins 1007 0253.

Samadzadeh S, Brauns R, Rosenthal D, Hefter H (2021) The impact of SARS-CoV-2 pandemic lockdown on a botulinum toxin outpatient clinic in Germany. Toxins 13:101. https://doi.org/10.3390/toxin s13020101

Santamato A, Facciorusso S, Spina S, Cinone N, Avvantaggiato C, Santoro L, Ciritella C, Smania N, Picelli A, Gasperini G, Molteni F, Baricich A, Fiore P (2021) Discontinuation of botulinum neurotoxin type-A treatment during COVID-19 pandemic: an Italian survey in post-stroke and traumatic brain injury patients living with spasticity. Eur J Phys Rehabil Med 57:424-433. https://doi. org/10.23736/S1973-9087.20.06478-3

Simpson DM, Hallett M, Ashman EJ, Comella CL, Green MW, Gronseth GS, Armstrong MJ, Gloss D, Potrebic S, Jankovic J, Karp BP, Naumann M, So YT, Yablon SA (2016) Practice guideline update summary: Botulinum neurotoxin for the treatment of blepharospasm, cervical dystonia, adult spasticity, and headache: Report of the Guideline Development Subcommittee of the American Academy of Neurology. Neurology 86:1818-1826. https://doi.org/ 10.1212/WNL.0000000000002560

Tarantino D, Gnasso R, Migliore F, Iommazzo I, Sirico F, Corrado B (2021) The effects of COVID-19 pandemic countermeasures on patients receiving botulinum toxin therapy and on their caregivers: a study from an Italian cohort. Neurol Sci 42:3071-3077. https:// doi.org/10.1007/s10072-021-05282-3

Publisher's Note Springer Nature remains neutral with regard to jurisdictional claims in published maps and institutional affiliations. 